\title{
Current Taxonomical Situation of Streptococcus suis
}

\author{
Masatoshi Okura ${ }^{1}$, Makoto Osaki ${ }^{1}$, Ryohei Nomoto ${ }^{2}$, Sakura Arai ${ }^{3}$, Ro Osawa ${ }^{4}$, \\ Tsutomu Sekizaki ${ }^{3}$ and Daisuke Takamatsu ${ }^{1,5, *}$
}

1 Division of Bacterial and Parasitic Diseases, National Institute of Animal Health, National Agriculture and Food Research Organization, 3-1-5 Kannondai, Tsukuba, Ibaraki 305-0856, Japan; mokura@affrc.go.jp (M.O.); osaki@affrc.go.jp (M.Os.)

2 Department of Infectious Diseases, Kobe Institute of Health, 4-6-5 Minatojima-Nakamachi, Chuo-ku, Kobe, Hyogo 650-0045, Japan; ryohei_nomoto@office.city.kobe.lg.jp

3 Research Center for Food Safety, Graduate School of Agricultural and Life Sciences, The University of Tokyo, 1-1-1 Yayoi, Bunkyo-ku, Tokyo 113-8657, Japan; sakurairo1218@yahoo.co.jp (S.A.); asekizak@mail.ecc.u-tokyo.ac.jp (T.S.)

4 Organization for Advanced Science and Technology, Kobe University, 1-1 Rokko-dai, Nada-ku, Kobe, Hyogo 657-8501, Japan; tamie@opal.kobe-u.ac.jp

5 The United Graduate School of Veterinary Sciences, Gifu University, 1-1 Yanagido, Gifu, Gifu 501-1193, Japan

* Correspondence: p1013dt@affrc.go.jp; Tel.: +81-29-838-7754

Academic Editor: Mariela Segura

Received: 9 May 2016; Accepted: 20 June 2016; Published: 24 June 2016

\begin{abstract}
Streptococcus suis, a major porcine pathogen and an important zoonotic agent, is considered to be composed of phenotypically and genetically diverse strains. However, recent studies reported several "S. suis-like strains" that were identified as S. suis by commonly used methods for the identification of this bacterium, but were regarded as distinct species from $S$. suis according to the standards of several taxonomic analyses. Furthermore, it has been suggested that some S. suis-like strains can be assigned to several novel species. In this review, we discuss the current taxonomical situation of S. suis with a focus on (1) the classification history of the taxon of S. suis; (2) S. suis-like strains revealed by taxonomic analyses; (3) methods for detecting and identifying this species, including a novel method that can distinguish S. suis isolates from S. suis-like strains; and (4) current topics on the reclassification of $S$. suis-like strains.
\end{abstract}

Keywords: Streptococcus suis; taxonomic analyses; species demarcation; S. suis-like strains

\section{Introduction}

Streptococcus suis is an important swine pathogen responsible for severe economic loss to the global swine industry [1-3]. S. suis can cause a variety of diseases, including meningitis, sepsis, endocarditis, arthritis, and pneumonia [1-3], while healthy pigs frequently carry this bacterium, particularly in their upper respiratory tracts and tonsils [4]. S. suis is also recognized as an emerging zoonotic pathogen that can be transmitted to humans from infected pigs or contaminated raw pork products $[1-3,5]$. In addition to pigs and humans, S. suis infection sporadically occurs in other animals, such as cattle, sheep, goats, boars, horses, cats, dogs, and birds $[1,6,7]$.

S. suis strains were serologically classified on the basis of the different antigenicity of their capsular polysaccharides (CPSs), and 35 serotypes (serotypes 1-34 and serotype 1/2 that reacts with both serotypes 1 and 2 antisera) have been reported [8-13]. In addition, the new serotype Chz was recently proposed [14]. Serotyping of S. suis is mainly performed for the identification and diagnosis of clinical isolates. Most $S$. suis isolates from diseased pigs belong to a limited number of serotypes, including serotypes 2, 3, 7, and 9; however, the distribution of serotypes from clinical cases differs depending on the geographic location (e.g., serotypes 2 and 3 are the most prevalent serotypes in Canada and 
the United States, while serotype 9 is the most frequently found in some European countries [2]). In humans, most clinical cases were associated with serotype 2 strains [2]. On the contrary, isolates from healthy pigs and other animals were usually classified into more diversified serotypes, and serologically untypable strains were also frequently found in these animals $([2,15,16]$ and unpublished observation), implying that more serotypes are present in S. suis than those reported to date. S. suis strains have been genotyped into many different sequence types (STs) by multi-locus sequence typing (MLST), which is used in many laboratories globally to genotype this species [2,17]. As of April 2016, more than 700 STs were known in S. suis (MLST datasets are available from PubMLST [18]). These previous studies indicate that phenotypically and genotypically diverse strains are included in the taxon S. suis. However, the presence of several "S. suis-like strains" has recently begun to be reported. These strains had been identified as $S$. suis by the commonly used identification methods for this species, but they were regarded as non-S. suis strains when reverified by several taxonomic analyses [19-21]. That is, demarcation of the species S. suis is currently becoming obscure. In this review, to help understand the current taxonomical situation of $S$. suis, we discuss previous studies on this species with a focus on (1) the taxonomic classification history of S. suis; (2) S. suis-like strains identified by taxonomic analyses; (3) methods for the detection and identification of S. suis; and (4) current topics on the reclassification of S. suis-like strains.

\section{Taxonomic and Serological Classification Histories of S. suis}

Since the 1930s, streptococci have been classified by Lancefield grouping, which is based on the carbohydrate composition of bacterial cell wall antigens [22]. In the early 1960s, De Moor [23] assigned the Streptococcus strains from outbreaks and sporadic cases of septicemic infection in pigs into Lancefield groups designated R, S, RS, and T. In 1966, Elliott [8] revealed that Moor's groups R and $S$ were subgroups of Lancefield group $D$ and regarded the strains of these groups as the new species "Streptococcus suis". Furthermore, it was demonstrated that the major antigens of Moor's groups $\mathrm{R}$ and $\mathrm{S}$ originated from their CPSs rather than their cell wall materials [8,9]. Then, Moor's groups $S$, R, and RS streptococci were reclassified as $S$. suis serotypes 1,2 , and $1 / 2$, respectively $[8,9]$. In 1983, six new serotypes (serotypes 3-8) were described by Perch et al. [10]. However, at that time, the name S. suis had not yet been included in the Approved Lists of Bacterial Names [24]. The formal proposal of the name "S. suis" was finally made in 1987 by Kilpper-Balz and Schleifer [25], and then, 26 additional serotypes (serotypes 9-34) were described for this species during the period from 1989 to 1995 [11-13]. In 2013, isolation of several S. suis serotype 21/29 strains from healthy pigs was reported [15]. Furthermore, in 2015, Pan et al. identified the novel serotype Chz in S. suis isolates from pigs with meningitis [14]. These taxonomical and serological classification histories of S. suis are summarized in Figure 1. 


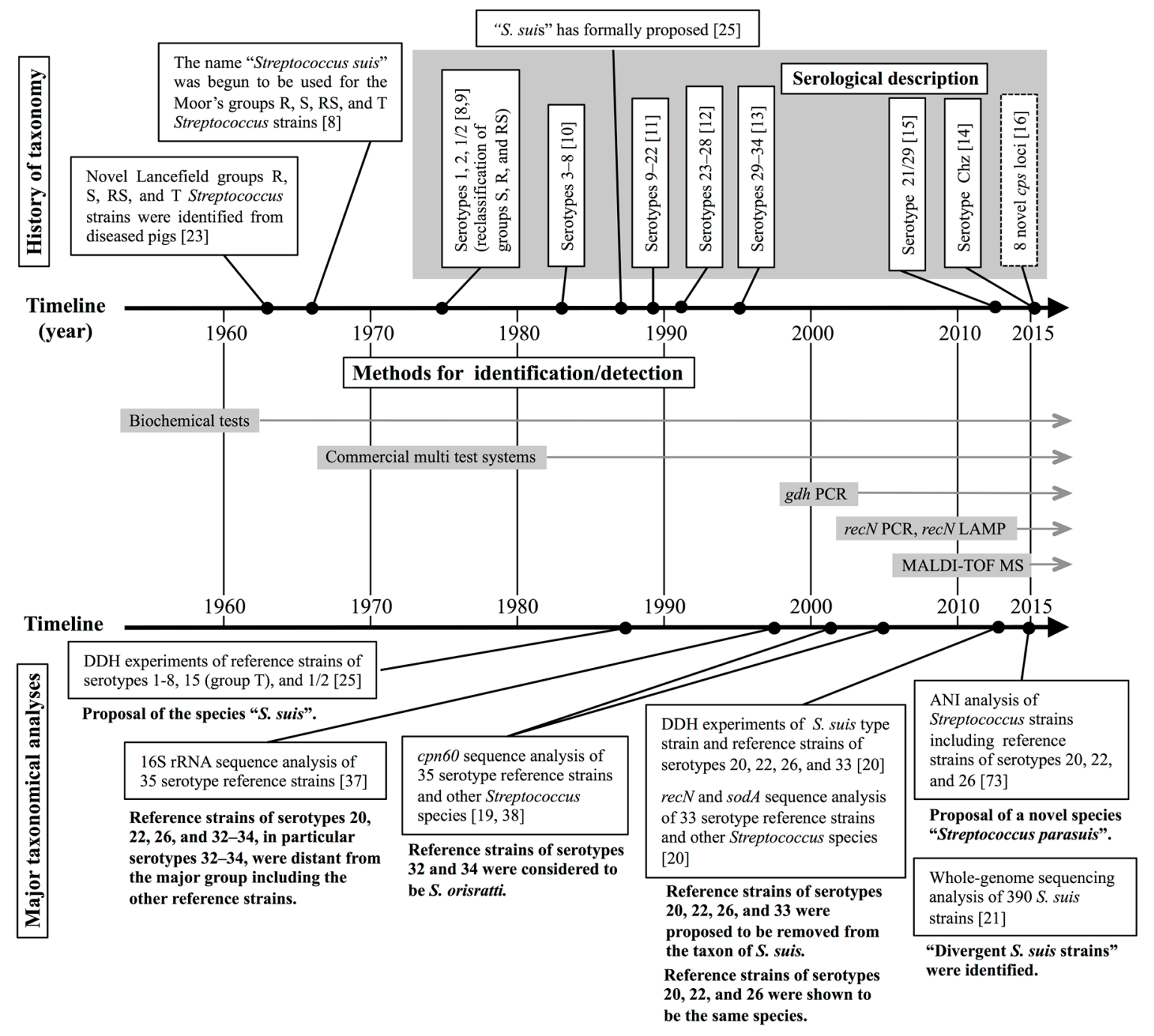

Figure 1. Timeline summary on the history of the taxon, serological description, identification/detection methods, and major taxonomical analyses (including the findings) of S. suis. DDH, DNA-DNA hybridization. ANI, average nucleotide identity.

\section{Several Taxonomic Analyses Revealed that Six S. suis Serotype Reference Strains are not S. suis}

\subsection{Taxonomic Standards for Species Delineation and Taxonomic Approaches for Phylogenetic Relationships in Bacteria}

In bacteria, a DNA-DNA hybridization (DDH) similarity of $\geqslant 70 \%$ is the gold standard for assigning two strains to the same species [26,27]. However, researchers are hesitant to use DDH experiments due to the complex and time-consuming nature of the technique [28-30]. In the 1990s, the cost, technology, and methodologies of DNA sequencing improved dramatically, and many centers then possessed DNA sequencers. Subsequently, many taxonomic and phylogenetic studies have been conducted on the basis of the sequences of specific housekeeping genes and/or other polyphasic data including biochemical characteristics (reviewed in [31]).

In 1994, Stackebrandt and Goebel [32] suggested that sequence analysis of the 16S rRNA gene is potentially useful for the definition of a species in bacteria. The accumulated data on 16S rRNA gene sequences revealed that the correlation between the 16S rRNA sequence similarities and DDH values obtained for the same strain pairs is not linear [32,33]. However, in the dataset analyzed to date, it has been demonstrated that, below a threshold value of 97\% 16S rRNA sequence similarity, the corresponding DDH values were always lower than 70\% [32-34]. Therefore, it is now generally 
accepted that two strains are regarded as distinct species when the 16S rRNA sequence similarity between them is less than $97 \%$ [27,32], although higher threshold values $(98.7 \%-99.0 \%$ or $98.2 \%-99.0 \%)$ have been recommended in several studies [33,34].

Sequencing analyses based on other housekeeping genes were also utilized for the discrimination of bacterial species because of the greater discriminating power than that of the 16S rRNA gene [31]. In Streptococcus species, the sequences of $\operatorname{sod} A$, encoding the manganese-dependent superoxide dismutase, and $r e c N$, encoding a recombination/repair protein, displayed low similarity values at the species level and a high divergence value at the subspecies level relative to those of other housekeeping genes [35]. Furthermore, the minimal interspecies divergence in the sequences of cpn60 ( $g r o E L)$, encoding the 60-kDa heat shock protein, was higher than those of other housekeeping genes in the Streptococcus species analyzed [36]. These previous studies suggested that sequence comparisons of cpn60, sodA, and recN are useful for identifying Streptococcus species and subspecies and conducting phylogenetic analysis.

\subsection{Taxonomic Studies Using S. suis Serotype Reference Strains}

DDH experiments on S. suis were conducted using 16 Streptococcus strains including 10 S. suis reference strains (serotypes 1-8,1/2, and an original Moor's group T strain that is currently assigned as the serotype 15 reference strain) for the formal proposal of the species "S. suis" [25]. All analyzed S. suis strains were confirmed to be the same species according to the DDH values (more than $80 \%$ ) [25]. However, until a study in 2013 [20] (see below), no additional DDH data on S. suis strains had been reported, and reference strains of novel serotypes described in the interim (serotypes 9-14 and 16-34) were identified as S. suis on the basis of the biochemical characteristics of the strains [11-13].

In 1998, Chatellier et al. [37] reported a 16S rRNA sequencing analysis of 35 S. suis serotype reference strains (serotypes 1-34 and 1/2). In their data, the reference strains of serotypes 20, 22, 26, and 32-34 were located distant from the other 29 reference strains on the 16S rRNA-based phylogenetic tree [37]. In addition, the reference strains of serotypes 20, 22, 26, and 32-34 exhibited 16S rRNA sequence similarity values with the other 29 reference strains of less than $97 \%$ (serotypes $32-34$ ) or $96.76 \%-98.27 \%$ (serotypes 20, 22, and 26) [37]. According to the generally accepted or recommended taxonomic criteria of $16 \mathrm{~S}$ rRNA sequence similarity, these six serotype reference strains are suggested to be distinct species from S. suis. Indeed, Chatellier et al. demonstrated that on the 16S rRNA-based phylogenetic tree, the serotype 33 reference strain was more related to Streptococcus acidominimus than to the major group of S. suis isolates and that serotype 32 and 34 reference strains were more closely related to the pyogenic group of Streptococcus, which includes Streptococcus agalactiae, Streptococcus parauberis, Streptococcus porcinus, and Streptococcus uberis [37].

The S. suis reference strains of serotypes 20,22, 26, and 32-34 were also separated from the other 29 reference strains via phylogenetic analysis based on the cpn60 sequence [19,38]. In Streptococcus species, phylogenies inferred from cpn60 sequence comparisons were found to be more discriminative than those inferred from 16S rRNA gene sequence comparisons [36]. Within S. suis, the cpn60 sequences also displayed a higher level of diversity among the serotype reference strains than the 16S rRNA sequences [38]. Nevertheless, the cpn60 sequences of serotype 32 and 34 reference strains shared more than $99 \%$ nucleotide identity with that of the Streptococcus orisratti type strain [19]. In contrast, the identities of the cpn60 sequences between $S$. orisratti and the other $S$. suis strains included in the study were only $78 \%-79 \%$ [19]. Taking these results into account, S. suis reference strains of serotypes 32 and 34 are currently considered to be $S$. orisratti [19].

In 2013, Tien et al. [20] demonstrated that the S. suis reference strains of serotypes 20, 22, 26, and 33 were clearly distinguished from the other 29 serotype reference strains (serotypes 1-19, 21, 23-25, 27-31, and $1 / 2$ ) by phylogenetic analyses using $\operatorname{sod} A$ and $\operatorname{rec} N$ sequences. In addition, these four reference strains exhibited DDH values of less than $70 \%$ with the S. suis type strain $(13.96 \%-33.87 \%)$ [20]. From these findings, the authors proposed that the serotype 20,22, 26, and 33 strains should be removed from the taxon of S. suis [20]. 
The aforementioned findings on the taxonomic positions of the serotype 20, 22, 26, and 32-34 reference strains are summarized in Figure 1. These findings suggest that some non-S. suis strains may be included with the isolates identified as "S. suis" on the basis of their biochemical characteristics. Such non-S. suis strains (i.e., strains which were previously identified as S. suis but which are currently considered not to be S. suis) are referred to as "S. suis-like strains" throughout this review, for convenience. Precise identification of S. suis and S. suis-like strains may help us understand the epidemiology of this important zoonotic disease more accuracy; however, it is difficult to discriminate S. suis-like strains from "authentic S. suis" by commonly used routine methods for the identification of S. suis. To solve this problem, novel identification and detection methods for S. suis have recently been developed. In the next section, we summarize those novel methods as well as the standard methods, which have been used in the majority of laboratories for many years in the identification and detection of this species.

\section{Methods for Identifying and Detecting S. suis}

A timeline summary of the history of the methods for the identification/detection of S. suis is shown in Figure 1.

\subsection{Routine Methods for Identifying and Detecting S. suis}

S. suis is a gram-positive coccus arranged in pairs, short chains, or single $[39,40]$. On bovine or sheep blood agar plates, most $\mathrm{S}$. suis strains are alpha-hemolytic after $24 \mathrm{~h}$ of incubation at $37^{\circ} \mathrm{C}[39,40]$. Alpha-hemolytic and gram-positive coccus isolates can be presumptively identified as $S$. suis by four tests: no growth in $6.5 \% \mathrm{NaCl}$ agar, a negative Voges-Proskauer test, and the production of acid from either trehalose or salicin $[2,39,40]$. For more precise identification, serotyping is conducted after the following biochemical tests: arginine dihydrolase (positive), production of acid from lactose, sucrose, and inulin (positive), and production of acid from glycerol, mannitol, and sorbitol (negative) [2,40]. Commercial $\mathrm{API}^{\circledR}$ multitest systems can be also used for the identification of $S$. suis [41-43], but these tests sometimes misidentify the isolates [2,3]. In clinical cases in pigs with typical clinical symptoms of S. suis infection, it is relatively easy to identify S. suis using the aforementioned tests [2]. By contrast, in human cases, misidentification can occur due to a lack of cognizance of this pathogen [2]. It is also difficult to identify the isolates from clinically healthy pigs or other animals using the aforementioned biochemical properties because strains of other Streptococcus species that are phenotypically similar to S. suis can be recovered from the same sites $[2,3]$.

During the last decade, molecular biological approaches have been developed for detecting and identifying S. suis strains. One of the most widely used methods is a polymerase chain reaction (PCR) assay targeting the $S$. suis-distinctive sequences of the housekeeping gene $g d h$, encoding the glutamate dehydrogenase [44]. However, it was reported that certain S. suis isolates were not correctly identified as S. suis by this PCR [45]. In addition, isolates of other Streptococcus species (such as Streptococcus gallolyticus, Streptococcus gallinaceus, and Streptococcus ovis) could be misidentified as S. suis by this method [46,47]. One possible reason for these misidentifications is the design concept of the primers for the PCR. This $g d h$ PCR assay was originally developed to detect all 35 serotype reference strains (serotypes 1-34 and 1/2) [44]. When the $g d h$ PCR was developed, this design concept was reasonable because no strong evidence had been reported to reclassify some of the reference strains into other species. However, as described in an aforementioned section (Section 3.2), the S. suis serotype $20,22,26$, and 32-34 reference strains are currently considered to be distinct species from S. suis; that is, although this PCR system was extremely useful, it does not match the current taxonomical situation of $S$. suis.

Serotyping of $S$. suis is useful for identifying clinical isolates because the method will provide further confirmation of the pathogen's identity [2]. In particular, the detection of serotype 2 isolates is very important for diagnosing S. suis infection in humans. However, in S. suis, serotyping with all typing antisera is time-consuming, and preparing the antisera is not easy due to the high cost and labor 
associated with its production [48]. To solve these problems, several molecular biological approaches have been developed as practical and easy methods to aid in the serotyping of $S$. suis ([14,15,48-60] Summarized in Table 1). Some of these methods can discriminate almost all serotypes and be used as molecular serotyping methods (Table 1).

Table 1. Molecular biological approaches developed to aid in the serotyping of S. suis.

\begin{tabular}{|c|c|c|c|}
\hline Method & Detecting Serotypes and Descriptions ${ }^{\text {a }}$ & Year & Reference \\
\hline PCR (3 assays) & $\begin{array}{l}\text { Assay 1: Serotypes } 1 \text { and } 14 ; \\
\text { Assay 2: Serotypes } 2 \text { and } 1 / 2 \\
\text { Assay 3: Serotype } 9\end{array}$ & 1999 & [49] \\
\hline PCR & Serotype 7 & 1999 & {$[50]$} \\
\hline Multiplex-PCR & $\begin{array}{c}\text { Serotypes 1, 2, 1/2, 7, 9, and } 14 \\
\text { epf (a virulence-associated marker of S. suis) is also detected }\end{array}$ & 2002 & [51] \\
\hline Multiplex-PCR & $\begin{array}{l}\text { Serotypes } 2 \text { and } 1 / 2 \\
\text { S. suis-specific sequence of the } 16 \mathrm{~S} \text { rRNA gene is also detected }\end{array}$ & 2004 & [52] \\
\hline Multiplex-PCR & $\begin{array}{c}\text { Serotypes } 1,2,1 / 2,7,9 \text {, and } 14 \\
\text { epf, sly, } m r p, \operatorname{arc} A \text { (virulence-associated markers of } S . \text { suis), and S. suis-specific } \\
\text { sequence of } g d h \text { are also detected }\end{array}$ & 2006 & [53] \\
\hline PCR & Serotype 16 & 2011 & [54] \\
\hline Real-time PCR & Serotypes 2 and $1 / 2$ & 2011 & [55] \\
\hline PCR (8 assays) & $\begin{array}{l}\text { Assay 1: Serotype 3; Assay 2: Serotype 4; } \\
\text { Assay 3: Serotype 5; Assay 4: Serotype 8; } \\
\text { Assay 5: Serotype 10; Assay 6: Serotype 19; } \\
\text { Assay 7: Serotype 23; Assay 8: Serotype 25; }\end{array}$ & 2012 & [56] \\
\hline Multiplex-PCR (2 reaction sets) & $\begin{array}{c}15 \text { serotypes (serotypes } 1-5,7-10,14,16,19,23,25 \text {, and } 1 / 2) \\
\text { Reaction } 1 \text { : Serotypes } 1,2,1 / 2,3,4,7,9,14 \text {, and } 16 \\
\text { Reaction } 2 \text { : Serotypes } 5,8,10,19,23, \text { and } 25 \\
\text { In both reactions, the } S \text {. suis-specific sequence of the } g d h \text { gene is also detected }\end{array}$ & 2012 & [57] \\
\hline Multiplex-PCR (4 reaction sets) & $\begin{array}{r}33 \text { serotypes (serotypes } 1-31,33 \text {, and } 1 / 2 \text { ) and variant serotype } 21 / 29 \\
\text { Reaction } 1 \text { : Serotypes } 1-10,14 \text {, and } 1 / 2 \\
\text { Reaction } 2 \text { : Serotypes } 11-21 \\
\text { Reaction } 3 \text { : Serotypes } 22-33 \\
\text { Reaction } 4 \text { : Serotype } 21 / 29 \\
\text { In all reactions, the } S \text {. suis-specific sequence of the } t h r A \text { gene is also detected }\end{array}$ & 2013 & [15] \\
\hline LAMP & Serotypes 2 and $1 / 2$ & 2013 & [58] \\
\hline Multiplex-PCR (2-step assay) & $\begin{array}{c}\text { 35 serotypes (serotypes } 1-34 \text { and } 1 / 2 \text { ) } \\
\text { Step 1: classified into } 7 \text { groups (Group I-VII) } \\
\text { Group I: serotypes } 3,13 \text {, and } 18 \\
\text { Group II: serotypes 1,2,1/2,6,14, 16, and } 27 \\
\text { Group III: serotypes } 21,28,29 \text {, and } 30 \\
\text { Group IV: serotypes } 4,5,7,17,19 \text {, and } 23 \\
\text { Group V: serotypes } 8,15,20,22 \text {, and } 25 \\
\text { Group VI: serotypes } 9,10,11,12,24,26 \text {, and } 33 \\
\text { Group VII: serotypes } 31,32 \text {, and } 34 \\
\text { Step 2: classified into respective serotypes of each group } \\
\text { In all reactions, universally shared sequences of the 16S rRNA gene are } \\
\text { also detected }\end{array}$ & 2014 & [48] \\
\hline Multiplex-PCR (4 reaction sets) & $\begin{array}{c}29 \text { serotypes (serotypes } 1-19,21,23-25,27-31,33 \text {, and } 1 / 2 \text { ) } \\
\text { Reaction } 1 \text { : Serotypes } 1,2,1 / 2,3,7,9,11,14 \text {, and } 16 \\
\text { Reaction } 2 \text { : Serotypes } 4,5,8,12,18,19,24 \text {, and } 25 \\
\text { Reaction } 3 \text { : Serotypes } 6,10,13,15,17,23 \text {, and } 31 \\
\text { Reaction 4: Serotypes } 21,27,28,29, \text { and } 30 \\
\text { In all reactions, the S. suis-specific sequence of the } g d h \text { gene is also detected }\end{array}$ & 2014 & [59] \\
\hline PCR & Serotype Chz & 2015 & [14] \\
\hline luminex $x \mathrm{TAG}^{\circledR}$ assay $^{\mathrm{TM}}$ & 33 serotypes (serotypes $1-31,33$, and $1 / 2$ ) & 2015 & [60] \\
\hline
\end{tabular}

a. epf, encoding an extracellular factor; sly, encoding suilysin; $m r p$, encoding muramidase-released protein; $\operatorname{arc} A$, encoding arginine deiminase; $g d h$, encoding glutamate dehydrogenase; $\operatorname{th} r A$, encoding aspartokinase/homoserine dehydrogenase I; LAMP, loop-mediated isothermal amplification.

Matrix-assisted laser desorption ionization time-of-flight mass spectrum (MALDI-TOF MS) has recently emerged as a reliable high-throughput tool for the microbiological identification of clinical isolates [61]. MALDI-TOF MS-based identification has been reported for several Streptococcus species [62-66]. Recently, Pérez-Sancho et al. [67] reported the excellent performance of MALDI-TOF MS for the identification of S. suis. In their data, $96.9 \%$ of the tested S. suis isolates (125/129 isolates) 
were correctly identified using the $S$. suis MALDI Biotyper database updated with the spectra of three additional clinical isolates of serotypes 2, 7, and 9 [67]. However, because bacterial isolates identified as S. suis by $g d h$ PCR [44] were used for evaluating the accuracy of MALDI-TOF MS for identifying S. suis in the study, S. suis-like strains might be included in the tests. Therefore, for more accurate evaluation of the usefulness of the MALDI-TOF MS techniques and the database, re-identification of the tested 129 isolates using other methods such as S. suis-specific recN PCR (see below) and reassessment of the MALDI-TOF MS results using "authentic S. suis" will be needed.

\subsection{Novel Methods for the Precise Identification and Detection of S. suis}

Recently, Ishida et al. [47] considered the recent reclassification of this bacterium and developed a novel PCR assay for detecting S. suis strains. For this PCR assay, they selected recN as the target and designed two primers to detect only the serotype reference strains of authentic $S$. suis (i.e., serotype $1-19,21,23-25,27-31$, and $1 / 2$ reference strains). As expected, under optimized conditions, the novel PCR (recN PCR) assay detected these serotype reference strains successfully, whereas no product was generated from the serotype 20,22, 26, and 32-34 reference strains. Using recN PCR, a specific PCR product was also amplified from all 133 S. suis isolates of serotypes $1-5,7-9,11,12,15,16,25$, and 31 tested; however, no amplicon was generated from any of the 16 isolates identified as $S$. suis serotypes 20, 22, and 33. Furthermore, this assay did not generate any specific amplicons from any other bacterial strains tested, including S. gallinaceus and S. ovis type strains, which displayed positive reactions using $g d h$ PCR [47]. These findings suggest that the novel $r e c N$ PCR assay is capable of distinguishing authentic S. suis strains from those of other species including S. suis-like strains. In 2015, a loop-mediated isothermal amplification (LAMP) method targeting recN of $S$. suis was reported and revealed to be useful for detecting S. suis from raw pork meat [68]. As these novel PCR and LAMP assays become more popular, the diagnosis of $S$. suis infections will become more accurate, and our understanding of the epidemiology of this important zoonosis will improve.

\section{Current Topics on the Classification of S. suis-Like Strains}

\subsection{Whole-Genome Sequencing-Based Taxonomic Analyses in Bacteria}

As described in an aforementioned section (Section 3.1), DDH remains the gold standard for the definitive assignment of a bacterial strain to a species. However, the results of DDH cannot be cumulated in databases, and this is a major drawback of this method in the bioinformatics era [69]. Therefore, there has been a continuous demand for an alternative genotype-based standard to replace DDH values $[28,69]$. Since the late 2000s, cost-effective and high-throughput DNA sequencing technologies have made whole-genome sequencing of bacterial strains more widely accessible, and direct comparisons of whole-genome sequences between strains are currently and readily applicable to bacterial taxonomy [70]. Average nucleotide identity (ANI) based on computational comparisons of two genome sequences is one of the similarity indices correlated with DDH values [71]. ANI is a mean of the similarity values of the total genomic sequence shared between two strains [71,72], and it has been most widely used as a possible next-generation gold standard for species delineation [30,69,71,72]. At present, it is accepted that ANI values of $95 \%-96 \%$ correspond to a DDH value of $70 \%$, and they can be used as a cut-off point for a bacterial species boundary [69,72].

\subsection{Streptococcus parasuis and Divergent S. suis Strains}

DDH experiments performed by Tien et al. [20] indicated that the reference strains of serotypes 20,22 , and 26 belong to a single species taxonomically distinct from S. suis. To clarify the taxonomic position of these strains, Nomoto et al. [73] analyzed whole-genome sequences of the serotype 20, 22, and 26 reference strains and five additional Streptococcus strains that reacted with specific antisera of these serotypes and demonstrated that the ANI values among these eight strains were higher than the cut-off value for bacterial species (95.3\%-99.9\%), whereas the ANI values among the 
eight strains and strains belonging to the species S. suis $(88.1 \%-89.0 \%)$ were much lower than the proposed cut-off value [73]. On the basis of these results and the results of additional phylogenetic and phenotypic analyses, the research group formally proposed these strains as the novel species Streptococcus parasuis [73].

On the contrary, Baig et al. [21] revealed nine "divergent S. suis strains" that were distinct from other "normal S. suis isolates" according to whole-genome sequence-based phylogeny on 390 S. suis strains, including 375 isolates identified using the API ID 32 Strep system. These divergent S. suis strains were classified into three genomic clades (Clades 1-3). Among the three clades, Clade 3 included the S. suis reference strains of serotypes 20, 22, and 26 [21] that were proposed as S. parasuis by Nomoto et al. [73]. In this study, although all of the divergent $S$. suis strains were distinguished from normal S. suis isolates via phylogenetic analysis of the $\operatorname{recN}$ sequences, not all of the divergent S. suis strains could be discriminated from normal S. suis isolates by phylogenetic comparisons based on the 16S rRNA, sodA, and cpn60 sequences [20]. In addition, three divergent $S$. suis strains belonging to Clade 2 possessed CPS synthesis genes (cps genes) of $S$. suis serotype 4 reference strains [21,74]. In fact, two of these strains were serotyped as serotype 4 [21]. The phylogenies of 132 core genes shared between the nine divergent $S$. suis strains and strains of other streptococcal species demonstrated that these divergent $S$. suis strains were more closely related to normal $S$. suis isolates than to other streptococcal species [21]. From these results, the authors argued that reclassification of the divergent S. suis strains would be premature and that they should remain classified as divergent $S$. suis strains [21]. However, when attention is focused on only the Clade 3 strains, all of the strains, including S. parasuis strains (reference strains of serotypes 20,22, and 26), were clustered in the same clade in any of the phylogenetic trees shown in the study, and the clade was apparently separated from the clades of normal S. suis isolates and the other divergent $S$. suis strains (Clade 1 and 2 strains) [21]. Therefore, some of their data may support the reclassification of serotype 20, 22, and 26 reference strains by Nomoto et al. [73].

Recently, Okura et al. identified many S. suis-like strains isolated from diseased and healthy ruminants (cattle, sheep, and a goat) that should be assigned to a novel species (unpublished data). These $S$. suis-like strains were suggested to be the same species as the serotype 33 reference strain isolated from a diseased lamb by ANI analyses and 16S rRNA gene sequences (unpublished data). Interestingly, to the best of our knowledge, similar S. suis-like strains have not been isolated from pigs, suggesting this novel species prefers ruminants rather than pigs. These $S$. suis-like strains sometimes cause confusion in the diagnosis of streptococcal diseases of ruminants because they are identified as S. suis by routine methods for identifying Streptococcus species. Therefore, a formal proposal of a novel species name for these strains and the development of a novel identification method of this species would contribute to the avoidance of confusion in veterinary diagnostic laboratories.

The S. suis-like strains identified to date are summarized in Table 2. Isolation of S. suis-like strains from humans has not been reported hitherto. Although we cannot hope to determine at this stage whether all the human clinical isolates reported as S. suis were authentic S. suis or not, it is noteworthy that most of the human clinical isolates reported so far were serotype 2 , and no serotypes $20,22,26$, and 32-34 strains have been isolated from humans [2]. In addition, most human clinical isolates analyzed were classified into limited clonal complexes (CC1, CC20, CC25, CC28, CC104, CC221/234, and CC233/379) by MLST $[2,17,75-79]$, and as far as our and other groups analyzed by the whole-genome-based phylogenies, CC1, CC25, CC28, and CC104 strains from humans were grouped together with other authentic (normal) S. suis ([21] and unpublished observation). 
Table 2. "S. suis-like strains" reported or identified in previous studies.

\begin{tabular}{|c|c|c|c|c|}
\hline Strains & Serotype $^{a}$ & Source & Descriptions $^{b}$ & Reference \\
\hline EA1172.91 & 32 & Diseased pig (septicemia) & \multirow{2}{*}{$\begin{array}{l}\text { Serotype reference strains } \\
\text { Considered to be S. orisratti by } \\
\text { cpn } 60 \text { analysis }\end{array}$} & \multirow{2}{*}{ [19] } \\
\hline $92-2742$ & 34 & Diseased pig (aborted fetus) & & \\
\hline EA1832.92 & 33 & Diseased lamb (arthritis) & $\begin{array}{l}\text { Serotype reference strain } \\
\text { Shown to be a non-S. suis strain by DDH }\end{array}$ & {$[20]$} \\
\hline $86-5192$ & 20 & Diseased pig (unknown) & \multirow{3}{*}{$\begin{array}{l}\text { Serotype reference strains } \\
\text { Shown to be non-S. suis strains and the } \\
\text { same species by DDH and ANI } \\
\text { Reclassified as S. parasuis [73] or } \\
\text { considered to be divergent S. suis strains } \\
\text { (Classified into Clade } 3 \text { on the basis of the } \\
\text { whole-genome-based phylogeny [21]) }\end{array}$} & \multirow{3}{*}[20,21,73]{} \\
\hline $88-1861$ & 22 & Diseased calf (unknown) & & \\
\hline $89-4109-1$ & 26 & Diseased pig (unknown) & & \\
\hline SUT-286 & 20 & \multirow{4}{*}{ Healthy pigs (saliva) } & \multirow{4}{*}{$\begin{array}{l}\text { S. parasuis strains (SUT-286 is the } \\
\text { type strain) } \\
\text { Shown to be the same species by ANI }\end{array}$} & \multirow{4}{*}{ [73] } \\
\hline SUT-380 & 22 & & & \\
\hline SUT-319, 328 & $20 / 22$ & & & \\
\hline SUT-7 & $22 / 26$ & & & \\
\hline LSS7 & UT & Healthy pigs & $\begin{array}{l}\text { Divergent } S \text {. suis strain } \\
\text { Classified into Clade } 1 \text { by the whole } \\
\text { genome-based phylogeny }\end{array}$ & [21] \\
\hline SS007 & 4 & $\begin{array}{l}\text { Diseased pig } \\
\text { (systemic-brain infection) }\end{array}$ & \multirow{4}{*}{$\begin{array}{l}\text { Divergent } S \text {. suis strains } \\
\text { cps losus of LSS6 was similar to cps } 4 \text { locus } \\
\text { Classified into Clade } 2 \text { by the whole } \\
\text { genome-based phylogeny }\end{array}$} & \multirow{4}{*}[21]{} \\
\hline LSS19 & 4 & Healthy pig & & \\
\hline LSS6 & UT & Healthy pig & & \\
\hline SS1003 & 22 & $\begin{array}{l}\text { Diseased pig } \\
\text { (respiratory infection) }\end{array}$ & & \\
\hline LSS17 & UT & Healthy pig & $\begin{array}{l}\text { Divergent } S \text {. suis strain } \\
\text { Classified into Clade } 3 \text { by the whole } \\
\text { genome-based phylogeny }\end{array}$ & {$[21]$} \\
\hline SUT-283 & 20 & Healthy pig & \multirow{4}{*}{$\begin{array}{l}\text { recN PCR negative but } g d h \mathrm{PCR} \\
\text { positive strains }\end{array}$} & \multirow{4}{*}[47]{} \\
\hline FUT-29 & 20 & Pork & & \\
\hline GUT-182 & 22 & Diseased pig (endocarditis) & & \\
\hline $\begin{array}{l}\text { GUT-183-193 } \\
\text { (11 strains) }\end{array}$ & 33 & $\begin{array}{l}\text { Diseased calves } \\
\text { (endocarditis) }\end{array}$ & & \\
\hline More than 70 isolates & 33 and UT & $\begin{array}{l}\text { Diseased cattle, sheep, and a } \\
\text { goat (endocarditis, arthritis, } \\
\text { and pneumonia) } \\
\text { Healthy cattle (tonsil and } \\
\text { nasal cavity) }\end{array}$ & $\begin{array}{l}\text { recN PCR negative but } g d h \text { PCR positive } \\
\text { strains } \\
\text { Twenty of them analyzed by whole } \\
\text { genome sequencing were shown to be the } \\
\text { same species with serotype } 33 \text { reference } \\
\text { strain by ANI }\end{array}$ & Unpublished \\
\hline
\end{tabular}

\section{Conclusions}

S. suis, an important zoonotic agent, is composed of phenotypically and genetically diverse strains. Recently, several studies indicated the presence of "S. suis-like strains" that were revealed to be non-S. suis strains by taxonomic analyses based on genetic methods despite being previously identified as S. suis by biochemical tests and, in some cases, by clinical symptoms. Among the taxonomic analyses, $r e c N$ sequence-based phylogeny is, in particular, an easy and very powerful tool for the discrimination of "authentic S. suis" from these S. suis-like strains and other Streptococcus species. Therefore, PCR and LAMP assays designed on the basis of $r e c N$ sequences will be useful methods for more precise identification and detection of $S$. suis.

Classification of some S. suis-like strains, such as the "divergent S. suis strains", is currently controversial. Little is known about these $S$. suis-like strains, including their potential virulence, association with diseases, host specificity, ecological importance, and distinctive phenotypic or genetic properties useful for discriminating the strains from authentic $S$. suis. More extensive studies using a number of $S$. suis and S. suis-like strains will provide additional insights into the classification of these strains and make the species boundaries clear. 
Acknowledgments: Masatoshi Okura is supported by the Japan Society for the Promotion of Science, under KAKENHI Grants Numbers 26870840.

Author Contributions: Masatoshi Okura and Daisuke Takamatsu wrote the manuscript with input from the other authors.

Conflicts of Interest: The authors declare no conflicts of interest.

\section{Abbreviations}

The following abbreviations are used in this manuscript:

$\begin{array}{ll}\text { CPS } & \text { capsular polysaccharide } \\ \text { ST } & \text { Sequence type } \\ \text { DNA } & \text { deoxyribonucleic acid } \\ \text { DDH } & \text { DNA-DNA hybridization } \\ \text { 16S rRNA } & \text { 16 Svedberg units ribosomal-ribonucleic acid } \\ \text { API } & \text { analytical profile index } \\ \text { PCR } & \text { polymerase chain reaction } \\ \text { MALDI-TOF } & \text { Matrix-assisted laser desorption ionization } \\ \text { MS } & \text { time-of-flight mass spectrum } \\ \text { LAMP } & \text { loop-mediated isothermal amplification } \\ \text { ANI } & \text { average nucleotide identity } \\ \text { UT } & \text { unserotypable }\end{array}$

\section{References}

1. Staats, J.J.; Feder, I.; Okwumabua, O.; Chengappa, M.M. Streptococcus suis: Past and present. Vet. Res. Commun. 1997, 21, 381-407. [CrossRef] [PubMed]

2. Goyette-Desjardins, G.; Auger, J.P.; Xu, J.; Segura, M.; Gottschalk, M. Streptococcu suis, an important pig pathogen and emerging zoonotic agent-An update on the worldwide distribution based on serotyping and sequence typing. Emerg. Microbes Infect. 2014, 3, e45. [CrossRef] [PubMed]

3. Gottschalk, M.; Xu, J.; Calzas, C.; Segura, M. Streptococcus suis: A new emerging or an old neglected zoonotic pathogen. Future Microbiol. 2010, 5, 371-391. [CrossRef] [PubMed]

4. Gottschalk, M. Streptococcosis. In Diseases of Swine, 10th ed.; Zimmerman, J.J., Karriker, L.A., Ramirez, A., Schwartz, K.J., Stevenson, G.W., Eds.; Wiley-Blackwell: Ames, TA, USA, 2012; pp. 841-855.

5. Wertheim, H.F.; Nghia, H.D.; Taylor, W.; Schultsz, C. Streptococcus suis: An emerging human pathogen. Clin. Infect. Dis. 2009, 48, 617-625. [CrossRef] [PubMed]

6. Devriese, L.A.; Haesebrouck, F.; de Herdt, P.; Dom, P.; Ducatelle, R.; Desmidt, M.; Messier, S.; Higgins, R. Streptococcus suis infections in birds. Avian Pathol. 1994, 23, 721-724. [CrossRef] [PubMed]

7. Risco, D.; Fernández-Llario, P.; Cuesta, J.M.; García-Jiménez, W.L.; Gonçalves, P.; Martínez, R.; García, A.; Rosales, R.; Gómez, L.; de Mendoza, J.H. Fatal case of Streptococcus suis infection in a young wild boar (Sus. scrofa) from southwestern Spain. J. Zoo Wildl. Med. 2015, 46, 370-373. [CrossRef] [PubMed]

8. Elliott, S.D. Streptococcal infection in young pigs. I. An immunochemical study of the causative agent (PM streptococcus). J. Hyg. 1966, 64, 205-212. [CrossRef] [PubMed]

9. Windsor, R.S.; Elliott, S.D. Streptococcal infection in young pigs. IV. An outbreak of streptococcal meningitis in weaned pigs. J. Hyg. 1975, 75, 69-78. [CrossRef] [PubMed]

10. Perch, B.; Pedersen, K.B.; Henrichsen, J. Serology of capsulated streptococci pathogenic for pigs: Six new serotypes of Streptococcus suis. J. Clin. Microbiol. 1983, 17, 993-996. [PubMed]

11. Gottschalk, M.; Higgins, R.; Jacques, M.; Mittal, K.R.; Henrichsen, J. Description of 14 new capsular types of Streptococcus suis. J. Clin. Microbiol. 1989, 27, 2633-2636. [PubMed]

12. Gottschalk, M.; Higgins, R.; Jacques, M.; Beaudoin, M.; Henrichsen, J. Characterization of six new capsular types (23 through 28) of Streptococcus suis. J. Clin. Microbiol. 1991, 29, 2590-2594. [PubMed]

13. Higgins, R.; Gottschalk, M.; Boudreau, M.; Lebrun, A.; Henrichsen, J. Description of six new capsular types (29-34) of Streptococcus suis. J. Vet. Diagn. Investig. 1995, 7, 405-406. [CrossRef]

14. Pan, Z.; Ma, J.; Dong, W.; Song, W.; Wang, K.; Lu, C.; Yao, H. Novel variant serotype of Streptococcus suis isolated from piglets with meningitis. Appl. Environ. Microbiol. 2015, 81, 976-985. [CrossRef] [PubMed]

15. Liu, Z.; Zheng, H.; Gottschalk, M.; Bai, X.; Lan, R.; Ji, S.; Liu, H.; Xu, J. Development of multiplex PCR assays for the identification of the 33 serotypes of Streptococcus suis. PLoS ONE 2013, 8, e72070. [CrossRef] [PubMed] 
16. Zheng, H.; Ji, S.; Liu, Z.; Lan, R.; Huang, Y.; Bai, X.; Gottschalk, M.; Xu, J. Eight novel capsular polysaccharide synthesis gene loci identified in nontypeable Streptococcus suis isolates. Appl. Environ. Microbiol. 2015, 81, 4111-4119. [CrossRef] [PubMed]

17. King, S.J.; Leigh, J.A.; Heath, P.J.; Luque, I.; Tarradas, C.; Dowson, C.G.; Whatmore, A.M. Development of a multilocus sequence typing scheme for the pig pathogen Streptococcus suis: Identification of virulent clones and potential capsular serotype exchange. J. Clin. Microbiol. 2002, 40, 3671-3680. [CrossRef] [PubMed]

18. PubMLST. Available online: http://pubmlst.org/ssuis/ (accessed on 29 April 2016).

19. Hill, J.E.; Gottschalk, M.; Brousseau, R.; Harel, J.; Hemmingsen, S.M.; Goh, S.H. Biochemical analysis, cpn60 and 16S rDNA sequence data indicate that Streptococcus suis serotypes 32 and 34, isolated from pigs, are Streptococcus orisratti. Vet. Microbiol. 2005, 107, 63-69. [CrossRef] [PubMed]

20. Tien le, H.T.; Nishibori, T.; Nishitani, Y.; Nomoto, R.; Osawa, R. Reappraisal of the taxonomy of Streptococcus suis serotypes 20, 22, 26, and 33 based on DNA-DNA homology and sodA and recN phylogenies. Vet. Microbiol. 2013, 162, 842-849. [CrossRef] [PubMed]

21. Baig, A.; Weinert, L.A.; Peters, S.E.; Howell, K.J.; Chaudhuri, R.R.; Wang, J.; Holden, M.T.; Parkhill, J.; Langford, P.R.; Rycroft, A.N.; et al. Whole genome investigation of a divergent clade of the pathogen Streptococcus suis. Front. Microbiol. 2015, 6, 1191. [CrossRef] [PubMed]

22. Lancefield, R.C. A serological differentiation of human and other groups of hemolytic streptococci. J. Exp. Med. 1933, 57, 571-595. [CrossRef] [PubMed]

23. De Moor, C.E. Septicaemic infections in pigs, caused by haemolytic streptococci of new Lancefield groups designated R, S and T. Antonie. van Leeuwenhoek 1963, 29, 272-280. [CrossRef]

24. Skerman, V.B.D.; McGowan, V.; Sneath, P.H.A. Approved lists of bacterial names. Int. J. Syst. Bacteriol. 1980, 30, 225-420. [CrossRef]

25. Kilpper-Balz, R.; Schleifer, K.H. Streptococcus suis sp. nov. nom. rev. Int. J. Syst. Bacteriol. 1987, 37, 160-162. [CrossRef]

26. Wayne, L.G.; Brenner, D.J.; Colwell, R.R.; Grimont, P.D.; Kandler, O.; Krichevsky, M.I.; Moore, L.H.; Moore, W.E.C.; Murray, R.G.E.; Stackebrand, E.; et al. International Committee on Systematic Bacteriology. Report of the ad hoc committee on reconciliation of approaches to bacterial systematics. Int. J. Syst. Bacteriol. 1987, 37, 463-464. [CrossRef]

27. Tindall, B.J.; Rosselló-Móra, R.; Busse, H.J.; Ludwig, W.; Kämpfer, P. Notes on the characterization of prokaryote strains for taxonomic purposes. Int. J. Syst. Evol. Microbiol. 2010, 60, 249-266. [CrossRef] [PubMed]

28. Gevers, D.; Cohan, F.M.; Lawrence, J.G.; Spratt, B.G.; Coenye, T.; Feil, E.J.; Stackebrandt, E.; Van de Peer, Y.; Vandamme, P.; Thompson, F.L.; et al. Re-evaluating prokaryotic species. Nat. Rev. Microbiol. 2005, 3, 733-739. [CrossRef] [PubMed]

29. Janda, J.M.; Abbott, S.L. 16S rRNA gene sequencing for bacterial identification in the diagnostic laboratory: Pluses, perils, and pitfalls. J. Clin. Microbiol. 2007, 45, 2761-2764. [CrossRef] [PubMed]

30. Kim, M.; Oh, H.S.; Park, S.C.; Chun, J. Towards a taxonomic coherence between average nucleotide identity and 16S rRNA gene sequence similarity for species demarcation of prokaryotes. Int. J. Syst. Evol. Microbiol. 2014, 64, 346-351. [CrossRef] [PubMed]

31. Das, S.; Dash, H.R.; Mangwani, N.; Chakraborty, J.; Kumari, S. Understanding molecular identification and polyphasic taxonomic approaches for genetic relatedness and phylogenetic relationships of microorganisms. J. Microbiol. Methods 2014, 103, 80-100. [CrossRef] [PubMed]

32. Stackebrandt, E.; Goebel, B.M. Taxonomic note: A place for DNA-DNA reassociation and $16 \mathrm{~S}$ rRNA sequence analysis in the present species definition in bacteriology. Int. J. Syst. Bacteriol. 1994, 44, 846-849. [CrossRef]

33. Stackebrandt, E.; Ebers, J. Taxonomic parameters revisited: Tarnished gold standards. Microbiol. Today 2006, 33, 152-155.

34. Meier-Kolthoff, J.P.; Auch, A.F.; Klenk, H.P.; Göker, M. Genome sequence-based species delimitation with confidence intervals and improved distance functions. BMC Bioinformatics 2013, 14, 60. [CrossRef] [PubMed]

35. Glazunova, O.O.; Raoult, D.; Roux, V. Partial recN gene sequencing: A new tool for identification and phylogeny within the genus Streptococcus. Int. J. Syst. Evol. Microbiol. 2010, 60, 2140-2148. [CrossRef] [PubMed]

36. Glazunova, O.O.; Raoult, D.; Roux, V. Partial sequence comparison of the $r p o B$, sodA, groEL, and gyrB genes within the genus Streptococcus. Int. J. Syst. Evol. Microbiol. 2009, 59, 2317-2322. [CrossRef] [PubMed] 
37. Chatellier, S.; Harel, J.; Zhang, Y.; Gottschalk, M.; Higgins, R.; Devriese, L.A.; Brousseau, R. Phylogenetic diversity of Streptococcus suis strains of various serotypes as revealed by $16 \mathrm{~S}$ rRNA gene sequence comparison. Int. J. Syst. Bacteriol. 1998, 48, 581-589. [CrossRef] [PubMed]

38. Brousseau, R.; Hill, J.E.; Préfontaine, G.; Goh, S.H.; Harel, J.; Hemmingsen, S.M. Streptococcus suis serotypes characterized by analysis of chaperonin 60 gene sequences. Appl. Environ. Microbiol. 2001, 67, 4828-4833. [CrossRef] [PubMed]

39. Higgins, R.; Gottschalk, M. An update on Streptococcus suis identification. J. Vet. Diagn. Investig. 1990, 2 , 249-252. [CrossRef]

40. Hommez, J.; Devriese, L.A.; Henrichsen, J.; Castryck, F. Identification and characterization of Streptococcus suis. Vet. Microbiol. 1986, 11, 349-355. [CrossRef]

41. Tarradas, C.; Arenas, A.; Maldonado, A.; Luque, I.; Miranda, A.; Perea, A. Identification of Streptococcus suis isolated from swine: Proposal for biochemical parameters. J. Clin. Microbiol. 1994, 32, 578-580. [PubMed]

42. Tillotson, G.S. An evaluation of the API-20 STREP system. J. Clin. Pathol. 1982, 35, 468-472. [CrossRef] [PubMed]

43. Freney, J.; Bland, S.; Etienne, J.; Desmonceaux, M.; Boeufgras, J.M.; Fleurette, J. Description and evaluation of the semiautomated 4-hour rapid ID 32 Strep method for identification of streptococci and members of related genera. J. Clin. Microbiol. 1992, 30, 2657-2661. [PubMed]

44. Okwumabua, O.; O'Connor, M.; Shull, E. A polymerase chain reaction (PCR) assay specific for Streptococcus suis based on the gene encoding the glutamate dehydrogenase. FEMS Microbiol. Lett. 2003, 218, 79-84. [CrossRef] [PubMed]

45. Gottschalk, M.; Lacouture, S.; Bonifait, L.; Roy, D.; Fittipaldi, N.; Grenier, D. Characterization of Streptococcus suis isolates recovered between 2008 and 2011 from diseased pigs in Québec, Canada. Vet. Microbiol. 2013, 162, 819-825. [PubMed]

46. Tien le, H.T.; Sugiyama, N.; Duangsonk, K.; Tharavichitkul, P.; Osawa, R. Phenotypic and PCR-based identification of bacterial strains isolated from patients with suspected Streptococcus suis infection in northern Thailand. Jpn. J. Infect. Dis. 2012, 65, 171-174. [PubMed]

47. Ishida, S.; Tien le, H.T.; Osawa, R.; Tohya, M.; Nomoto, R.; Kawamura, Y.; Takahashi, T.; Kikuchi, N.; Kikuchi, K.; Sekizaki, T. Development of an appropriate PCR system for the reclassification of Streptococcus suis. J. Microbiol. Methods 2014, 107, 66-70. [CrossRef] [PubMed]

48. Okura, M.; Lachance, C.; Osaki, M.; Sekizaki, T.; Maruyama, F.; Nozawa, T.; Nakagawa, I.; Hamada, S.; Rossignol, C.; Gottschalk, M.; et al. Development of a two-step multiplex PCR assay for typing of capsular polysaccharide synthesis gene clusters of Streptococcus suis. J. Clin. Microbiol. 2014, 52, 1714-1719. [CrossRef] [PubMed]

49. Smith, H.E.; Veenbergen, V.; van der Velde, J.; Damman, M.; Wisselink, H.J.; Smits, M.A. The cps genes of Streptococcus suis serotypes 1,2, and 9: Development of rapid serotype-specific PCR assays. J. Clin. Microbiol. 1999, 37, 3146-3152. [PubMed]

50. Smith, H.E.; van Bruijnsvoort, L.; Buijs, H.; Wisselink, H.J.; Smits, M.A. Rapid PCR test for Streptococcus suis serotype 7. FEMS Microbiol. Lett. 1999, 178, 265-270. [CrossRef] [PubMed]

51. Wisselink, H.J.; Joosten, J.J.; Smith, H.E. Multiplex PCR assays for simultaneous detection of six major serotypes and two virulence-associated phenotypes of Streptococcus suis in tonsillar specimens from pigs. J. Clin. Microbiol. 2002, 40, 2922-2929. [CrossRef] [PubMed]

52. Marois, C.; Bougeard, S.; Gottschalk, M.; Kobisch, M. Multiplex PCR assay for detection of Streptococcus suis species and serotypes 2 and 1/2 in tonsils of live and dead pigs. J. Clin. Microbiol. 2004, 42, 3169-3175. [CrossRef] [PubMed]

53. Silva, L.M.; Baums, C.G.; Rehm, T.; Wisselink, H.J.; Goethe, R.; Valentin-Weigand, P. Virulence-associated gene profiling of Streptococcus suis isolates by PCR. Vet. Microbiol. 2006, 115, 117-127. [CrossRef] [PubMed]

54. Wang, K.; Fan, W.; Wisselink, H.; Lu, C. The cps locus of Streptococcus suis serotype 16: Development of a serotype-specific PCR assay. Vet. Microbiol. 2011, 153, 403-406. [CrossRef] [PubMed]

55. Nga, T.V.; Nghia, H.D.; Tu le, T.P.; Diep, T.S.; Mai, N.T.; Chau, T.T.; Sinh, D.X.; Phu, N.H.; Nga, T.T.; Chau, N.V.; et al. Real-time PCR for detection of Streptococcus suis serotype 2 in cerebrospinal fluid of human patients with meningitis. Diagn. Microbiol. Infect. Dis. 2011, 70, 461-467. [CrossRef] [PubMed]

56. Wang, K.; Sun, X.; Lu, C. Development of rapid serotype-specific PCR assays for eight serotypes of Streptococcus suis. J. Clin. Microbiol. 2012, 50, 3329-3334. [CrossRef] [PubMed] 
57. Kerdsin, A.; Dejsirilert, S.; Akeda, Y.; Sekizaki, T.; Hamada, S.; Gottschalk, M.; Oishi, K. Fifteen Streptococcus suis serotypes identified by multiplex PCR. J. Med. Microbiol. 2012, 61, 1669-1672. [CrossRef] [PubMed]

58. Zhang, J.; Zhu, J.; Ren, H.; Zhu, S.; Zhao, P.; Zhang, F.; Lv, H.; Hu, D.; Hao, L.; Geng, M.; et al. Rapid visual detection of highly pathogenic Streptococcus suis serotype 2 isolates by use of loop-mediated isothermal amplification. J. Clin. Microbiol. 2013, 51, 3250-3256. [CrossRef] [PubMed]

59. Kerdsin, A.; Akeda, Y.; Hatrongjit, R.; Detchawna, U.; Sekizaki, T.; Hamada, S.; Gottschalk, M.; Oishi, K. Streptococcus suis serotyping by a new multiplex PCR. J. Med. Microbiol. 2014, 63, 824-830. [PubMed]

60. Bai, X.; Liu, Z.; Ji, S.; Gottschalk, M.; Zheng, H.; Xu, J. Simultaneous detection of 33 Streptococcus suis serotypes using the luminex xTAG $^{\circledR}$ assay $^{\mathrm{TM}}$. J. Microbiol. Methods 2015, 117, 95-99. [CrossRef] [PubMed]

61. Pavlovic, M.; Huber, I.; Konrad, R.; Busch, U. Application of MALDI-TOF MS for the Identification of Food Borne Bacteria. Open Microbiol. J. 2013, 7, 135-141. [CrossRef] [PubMed]

62. Cherkaoui, A.; Emonet, S.; Fernández, J.; Schorderet, D.; Schrenzel, J. Evaluation of matrix-assisted laser desorption ionization-time of flight mass spectrometry for rapid identification of Beta-hemolytic streptococci. J. Clin. Microbiol. 2011, 49, 3004-3005. [CrossRef] [PubMed]

63. Hinse, D.; Vollmer, T.; Erhard, M.; Welker, M.; Moore, E.R.; Kleesiek, K.; Dreier, J. Differentiation of species of the Streptococcus bovis/equinus-complex by MALDI-TOF mass spectrometry in comparison to sodA sequence analyses. Syst. Appl. Microbiol. 2011, 34, 52-57. [CrossRef] [PubMed]

64. Ikryannikova, L.N.; Filimonova, A.V.; Malakhova, M.V.; Savinova, T.; Filimonova, O.; Ilina, E.N.; Dubovickaya, V.A.; Sidorenko, S.V.; Govorun, V.M. Discrimination between Streptococcus pneumoniae and Streptococcus mitis based on sorting of their MALDI mass spectra. Clin. Microbiol. Infect. 2013, 19, 1066-1071. [CrossRef] [PubMed]

65. Werno, A.M.; Christner, M.; Anderson, T.P.; Murdoch, D.R. Differentiation of Streptococcus pneumoniae from non-pneumococcal streptococci of the Streptococcus mitis group by matrix-assisted laser desorption ionization-time of flight mass spectrometry. J. Clin. Microbiol. 2012, 50, 2863-2867. [CrossRef] [PubMed]

66. Woods, K.; Beighton, D.; Klein, J.L. Identification of the 'Streptococcus anginosus group' by matrix-assisted laser desorption ionization-Time-of-flight mass spectrometry. J. Med. Microbiol. 2014, 63, 1143-1147. [CrossRef] [PubMed]

67. Pérez-Sancho, M.; Vela, A.I.; García-Seco, T.; Gottschalk, M.; Domínguez, L.; Fernández-Garayzábal, J.F. Assessment of MALDI-TOF MS as alternative tool for Streptococcus suis identification. Front. Public Health 2015, 3, 202. [CrossRef] [PubMed]

68. Arai, S.; Tohya, M.; Yamada, R.; Osawa, R.; Nomoto, R.; Kawamura, Y.; Sekizaki, T. Development of loop-mediated isothermal amplification to detect Streptococcus suis and its application to retail pork meat in Japan. Int. J. Food. Microbiol. 2015, 208, 35-42. [CrossRef] [PubMed]

69. Richter, M.; Rosselló-Móra, R. Shifting the genomic gold standard for the prokaryotic species definition. Proc. Natl. Acad. Sci. USA 2009, 106, 19126-19131. [CrossRef] [PubMed]

70. Chun, J.; Rainey, F.A. Integrating genomics into the taxonomy and systematics of the Bacteria and Archaea. Int. J. Syst. Evol. Microbiol. 2014, 64, 316-324. [CrossRef] [PubMed]

71. Konstantinidis, K.T.; Tiedje, J.M. Genomic insights that advance the species definition for prokaryotes. Proc. Natl. Acad. Sci. USA 2005, 102, 2567-2572. [CrossRef] [PubMed]

72. Goris, J.; Konstantinidis, K.T.; Klappenbach, J.A.; Coenye, T.; Vandamme, P.; Tiedje, J.M. DNA-DNA hybridization values and their relationship to whole-genome sequence similarities. Int. J. Syst. Evol. Microbiol. 2007, 57, 81-91. [CrossRef] [PubMed]

73. Nomoto, R.; Maruyama, F.; Ishida, S.; Tohya, M.; Sekizaki, T.; Osawa, R. Reappraisal of the taxonomy of Streptococcus suis serotypes 20, 22 and 26: Streptococcus parasuis sp. nov. Int. J. Syst. Evol. Microbiol. 2015, 65, 438-443. [CrossRef] [PubMed]

74. Okura, M.; Takamatsu, D.; Maruyama, F.; Nozawa, T.; Nakagawa, I.; Osaki, M.; Sekizaki, T.; Gottschalk, M.; Kumagai, Y.; Hamada, S. Genetic analysis of capsular polysaccharide synthesis gene clusters from all serotypes of Streptococcu suis: Potential mechanisms for generation of capsular variation. Appl. Environ. Microbiol. 2013, 79, 2796-2806. [CrossRef] [PubMed]

75. Takamatsu, D.; Wongsawan, K.; Osaki, M.; Nishino, H.; Ishiji, T.; Tharavichitkul, P.; Khantawa, B.; Fongcom, A.; Takai, S.; Sekizaki, T. Streptococcus suis in humans, Thailand. Emerg. Infect. Dis. 2008, 14, 181-183. [CrossRef] [PubMed] 
76. Kerdsin, A.; Dejsirilert, S.; Puangpatra, P.; Sripakdee, S.; Chumla, K.; Boonkerd, N.; Polwichai, P.; Tanimura, S.; Takeuchi, D.; Nakayama, T.; et al. Genotypic profile of Streptococcus suis serotype 2 and clinical features of infection in humans, Thailand. Emerg. Infect. Dis. 2011, 17, 835-842. [CrossRef] [PubMed]

77. Schultsz, C.; Jansen, E.; Keijzers, W.; Rothkamp, A.; Duim, B.; Wagenaar, J.A.; van der Ende, A. Differences in the population structure of invasive Streptococcus suis strains isolated from pigs and from humans in The Netherlands. PLoS ONE 2012, 7, e33854. [CrossRef] [PubMed]

78. Kerdsin, A.; Dejsirilert, S.; Sawanpanyalert, P.; Boonnark, A.; Noithachang, W.; Sriyakum, D.; Simkum, S.; Chokngam, S.; Gottschalk, M.; Akeda, Y.; et al. Sepsis and spontaneous bacterial peritonitis in Thailand. Lancet 2011, 378, 960. [CrossRef]

79. Hatrongjit, R.; Kerdsin, A.; Gottschalk, M.; Hamada, S.; Oishi, K.; Akeda, Y. Development of a multiplex PCR assay to detect the major clonal complexes of Streptococcus suis relevant to human infection. J. Med. Microbiol. 2016, 65, 392-396. [CrossRef] [PubMed]

(C) 2016 by the authors; licensee MDPI, Basel, Switzerland. This article is an open access article distributed under the terms and conditions of the Creative Commons Attribution (CC-BY) license (http://creativecommons.org/licenses/by/4.0/). 